\title{
Performance evaluation of developed lab scale fermenter
}

\section{AJIT M. KURE, SACHIN R. PATIL AND VIKAS G. JADHAO}

Received : 16.07.2016; Revised : 01.09.2016; Accepted : 16.09.2016

See end of the Paper for authors' affiliation

Correspondence to :

\section{AJIT M. KURE}

Department of Agricultural Engineering, Maharashtra Institute of Technology, AURANGABAD (M.S.) INDIA Email : ajitkure@gmail.com
-ABSTRACT : Processing of raw agricultural produce works as a backbone of agricultural sector. Day by day to fulfill the need of increasing population processed food requires, maintaining quality of raw product as well as to enhance the market rate.This fermentation is done with the breakdown of complex material into the fermented product. Due to such characteristics fermentation helps to make higher growth of agricultural sector in our economy. Fermentation can be done by various ways but basically it may be aerobic and anaerobic kind. In another group it divided as solid state and submerged fermentation. For submerged condition fermentation needs a fermenter. It is a cylindrical vessel with having features like aeration system, agitation unit and monitoring as well as to control parameters of fermentation media. The efficient lab scale fermenter development was started with the selection of vessel body as of stainless steel-316 food grade material because of currently available market fermenter have problems with their glass body, sterilization, construction etc. So as per design consideration with aspect ratio 3:1 and working capacity of 2.0 lit., fermenter body and its assembly parts were developed. Design of fermenter makes feasible to use it as for aerobic as well as anaerobic condition also. The performance evaluation of developed fermenter was carried out on product basis in which the anaerobic fermented product selected as guava cider and in case aerobic it was alpha amylase enzyme. In anaerobic fermentation by using Sacchromyces cerevisiae yeast and fermenter, guava pulp kept for fermentation for 36 hrs trials. After centrifugation the cider formed with the features like average $\mathrm{pH}=4.17$, TSS $=4.7^{\circ} \mathrm{Brix}$ and alcohol content $=5.33$ per cent. Similarly with the same pulp and proportion fermentation was carried out in glass bottle as a comparative study. In this case also the yield of cider formed in fermenter was observed 10.50 per cent more than in glass bottle. In aerobic condition fermenter model set up was done with aeration unit and with the help of Bacillus subtilis, fermentation of chemical media was carried out for $24 \mathrm{hrs}$ at a $\mathrm{pH}$ 7. After fermentation time centrifugation was done and crude enzyme collected. By testing its average enzyme activity were observed as $0.22 \mathrm{U} / \mathrm{ml}$ and compared with standard maltose curve gave significant results as maltose release $0.42 \mathrm{mg}$. The developed fermenter of 2.0 lit. working capacity have features like multiple use, in situ sterilization, rigid structure, simple assembly, easy handling and affordable cost of Rs.27313/-.

- KEY WORDS : Fermentation, Aerobic, Anaerobic, Fermenter, Cider, Amylase

— HOW TO CITE THIS PAPER : Kure, Ajit M., Patil, Sachin R. and Jadhao, Vikas G. (2016). Performance evaluation of developed lab scale fermenter. Internat. J. Agric. Engg., 9(2) : 202-209, DOI: 10.15740/HAS/ IJAE/9.2/202-209. 